\title{
Acute kidney injury in pregnancy: a clinical challenge
}

\author{
Susana Machado ${ }^{1}$, Nuno Figueiredo ${ }^{1}$, \\ Andreia Borges ${ }^{1}$, Maria São José Pais ${ }^{2}$, \\ Luís Freitas ${ }^{1}$, Paulo Moura ${ }^{2}$, Mário Campos ${ }^{1}$
}

\author{
${ }^{1}$ Nephrology Department, Coimbra's University Hospitals, \\ Coimbra - Portugal \\ ${ }^{2}$ Daniel de Matos Maternity Hospital, Coimbra - Portugal
}

\begin{abstract}
The incidence of acute kidney injury in pregnancy declined significantly over the second half of the 20th century; however, it is still associated with major maternal and perinatal morbidity and mortality. A set of systemic and renal physiological adaptive mechanisms occur during a normal gestation that will constrain several changes in laboratory parameters of renal function, electrolytes, fluid and acid-base balances. The diagnosis of acute kidney injury in pregnancy is based on the serum creatinine increase. The usual formulas for estimating glomerular filtration rate are not validated in this population. During the first trimester of gestation, acute kidney injury develops most often due to hyperemesis gravidarum or septic abortion. In the third trimester, the differential diagnosis is more challenging for the obstetrician and the nephrologist and comprises some pathologies that are reviewed in this article: preeclampsia/HELLP syndrome, acute fatty liver of pregnancy and thrombotic microangiopathies.
\end{abstract}

Key words: Acute kidney injury, Preeclampsia, Pregnancy complications, Thrombotic microangiopathies

\section{INTRODUCTION}

Since 1960, the incidence of acute kidney injury (AKI) in pregnancy has been reduced significantly, and currently affects 1 per 20,000 pregnancies (1). The legalization of abortion contributed to this decline in most developed countries, leading to a reduction in the number of septic abortions the main cause of AKI in recent decades. Moreover, the ac- cessibility of improved prenatal care and diagnostic tools has been extended, and new therapeutics have been developed. Despite a favorable trend in incidence rates, maternal and perinatal morbidity and mortality remain significant problems.

\section{ADAPTIVE MECHANISMS IN PREGNANCY}

Some physiological changes in the urinary tract occur during normal pregnancy. There is an increase in kidney size by about $1-1.5 \mathrm{~cm}$ due to renal vascular and interstitial space volume expansion. Over $90 \%$ of pregnant women develop a physiological hydronephrosis of pregnancy that is characterized by a dilation of the calyces, renal pelvis and ureters (2). This anatomical abnormality may be present until the 16th postpartum week and promotes urinary stasis in the ureters, leading to the development of urinary tract infections. Three distinct mechanisms explain the development of this condition: (a) direct action of estrogen and progesterone, (b) inhibition of ureteral peristalsis by prostaglandin E2 and (c) partial mechanical obstruction by an increased uterus (3).

Systemic vascular resistance is reduced in pregnancy due to the low resistance of the uteroplacental vascular circuit and vasodilation. Possible factors leading to the vasodilation include a reduction in vascular responsiveness to norepinephrine and angiotensin II, increased endothelial prostacyclin production, increased prolactin and progesterone levels and increased nitric oxide synthesis by a route in which relaxin, produced by the corpus luteum and placenta, is implicated (4). The peripheral vasodilation determines a fall in blood pressure that can reach $10 \mathrm{~mm} \mathrm{Hg}$ during the first 24 weeks of gestation. The systemic vessel tone reduc- 
tion triggers compensatory mechanisms such as (a) cardiac output increase, (b) plasma volume increase and (c) reninangiotensin-aldosterone system activation (5). Regarding kidney hemodynamics, there is a renal plasma flow increase during pregnancy that can reach up to $85 \%$ in the second trimester (6). This change results from the cardiac output increase and afferent and efferent arteriole vasodilation, secondary to action of some humoral factors such as nitric oxide and relaxin synthesis or the resistance to aldosterone action. After conception, there is an increased glomerular filtration rate (GFR) that can reach $40 \%-65 \%$ of baseline throughout pregnancy $(6,7)$, and which subsides in the first 3 months postpartum. All of these hemodynamic changes explain a serum creatinine reduction in pregnant women to $0.4-0.5 \mathrm{mg} / \mathrm{dL}$.

In normal pregnancy, there is a decline of the plasma osmolarity (about $10 \mathrm{mOsm} / \mathrm{L}$ ) and plasma sodium concentration ( $5 \mathrm{mEq} / \mathrm{L}$ on average) due to a lower threshold for stimulation of thirst and vasopressin secretion. The mechanisms behind this are not completely understood, but human chorionic gonadotropin seems to have an important role (8).

Despite the GFR and sodium filtration fraction increase in pregnancy, the sodium balance is maintained by the rise of its reabsorption within the proximal convoluted tubule and in the distal portions of the nephron (under aldosterone influence). Taking into account the increase in serum aldosterone levels in pregnancy, one would expect a rise in potassium excretion. However, this does not occur, due to the competitive action of progesterone that connects to the mineralocorticoid receptors located in the distal portions of the nephron. The serum concentration of chlorine does not change with pregnancy. Often there is hypercalciuria in the pregnant woman, explained by an increase of the GFR and of the calcium gastrointestinal absorption due to a rise in 1,25-dihydroxyvitamin $\mathrm{D}_{3}$ levels (9).

The GFR increment also causes other physiological changes, including an increase of the uric acid clearance, an increase of the filtered glucose load and an increase of the glomerular filtration of amino acids. Therefore, the GFR increment and the increased permeability of glomerular capillaries to albumin raise the fractional excretion of albumin (10).

The hormonal change in gestation, particularly the increased progesterone levels, causes hyperventilation and mild respiratory alkalosis. A decrease of about $4 \mathrm{mEq} / \mathrm{L}$ in bicarbonate concentration is common in the pregnant woman.

All these physiological adaptive mechanisms have clinical consequences in laboratory parameters of renal function, electrolytes, fluid and acid-base balances that should be taken into account when dealing with a pregnant woman.

\section{AKI DIAGNOSIS IN PREGNANCY}

In the literature, there is a high degree of heterogeneity of diagnostic definitions of renal diseases in pregnancy (11), and therefore there is no validated definition for AKI. The use of the RIFLE classification, which focuses on the plasma creatinine percentage change and on the development of oliguria, is not consensual and further studies are necessary to demonstrate its usefulness in pregnant women. A creatinine level of $\geq 1 \mathrm{mg} / \mathrm{dL}$ or a rapid rise (by definition, in 48 hours) of $0.5 \mathrm{mg} / \mathrm{dL}$ above baseline should be investigated (12). However, the choice of GFR as a marker of renal function has advantages in pregnancy allowing the identification of an important compromise of renal function even in the presence of normal serum creatinine (11).

A standardization of GFR measurement in pregnancy is far from being reached. In 2007, 2 prospective studies were published to evaluate the accuracy of formulas for estimating GFR in pregnant women. Smith et al (13) compared the Modification of Diet in Renal Disease (MDRD) Study formula with inulin and creatinine clearance by 24-hour urine collection. On the other hand, Alper et al (14) compared both versions of the MDRD equation, the Cockcroft-Gault equation and creatinine clearance by 24-hour urine collection, in women with preeclampsia. Both concluded that the MDRD and Cockcroft-Gault formulas are inaccurate for the assessment of GFR in this specific population because the first underestimates the real GFR value, while the second overestimates it. Thus, creatinine clearance by 24 -hour urine collection remains the gold standard method for estimating GFR in pregnancy.

Routine obstetric care also includes proteinuria evaluation, as it is one of the diagnostic criteria for preeclampsia that will be discussed below in detail. Usually this assessment is performed by a semiquantitative method from a urine sample, but this shows a high rate of false-positive and false-negative results. Proteinuria quantification by 24-hour urine collection is the gold standard; however, some limitations are pointed out - for example, sampling errors. The use of the urine protein to creatinine ratio in the general population has increased because it is an accurate, reproducible and more convenient method for the patient. A meta-analysis involving 974 pregnant women (15), showed a sensitivity of $90 \%$ and specificity of $78 \%$ comparing this method (cutoff between 0.19 and 0.25 ) and the gold standard (proteinuria $>300 \mathrm{mg} / 24$ hours). However, its use in pregnancy is controversial, and published studies are discordant (16-18). In daily practice, it is reasonable to calculate the urine protein to creatinine ratio 
for diagnosis of preeclampsia; however, in questionable circumstances, 24-hour urine collection is recommended.

\section{Etiology of AKI in PREgnancy}

The differential diagnosis of AKI in pregnancy is a clinical challenge since we have to consider some pregnancy-associated specific diseases, but we cannot dismiss all other possible AKI causes that may affect women in the reproductive age group.

Usually, the development of AKI during pregnancy follows a bimodal distribution with 2 incidence peaks: one in the first trimester, caused by infections (usually involving septic abortion), and the other in the third trimester, due to late obstetric complications. As in the general population, the causes of AKI in pregnant women are divided into 3 groups: prerenal, intrarenal and postrenal (Tab. I). The prerenal causes are more common in the earlier stage of pregnancy due to hyperemesis gravidarum or acute tubular necrosis in the context of septic abortion. In the later stages, AKI development is more frequent and usually associated with preeclampsia, acute fatty liver of pregnancy, hemolytic uremic syndrome (HUS) and sepsis $(19,20)$. The following pregnancy-associated AKI causes will be discussed in more detail: (i) preeclampsia, (ii) hemolysis, elevated liver enzymes and low platelet count (HELLP) syndrome, (iii) acute fatty liver of pregnancy and (iv) thrombotic microangiopathies.

\section{TABLE I}

ACUTE KIDNEY INJURY ETIOLOGY IN PREGNANCY

\section{Causes}

\begin{tabular}{ll}
\hline & Hemorrhage \\
Prerenal & Hyperemesis gravidarum \\
& Congestive heart failure \\
& Sepsis
\end{tabular}

Acute tubular necrosis

Pyelonephritis

Renal cortical necrosis

Intrarenal

Thrombotic microangiopathy

Preeclampsia/HELLP syndrome

Acute fatty liver of pregnancy

Glomerulonephritis

Medications

\section{Postrenal Obstruction}

HELLP = hemolysis, elevated liver enzymes and low platelet count.

\section{Preeclampsia}

Preeclampsia is a syndrome characterized by the onset of hypertension and proteinuria after 20 weeks of gestation in a previously normotensive woman (21). This condition occurs in 3\%-8\% of pregnancies in the developed countries (22).

\section{Pathogenesis}

The pathogenesis of preeclampsia is not fully understood but involves defects in placentation and systemic endothelial activation.

At the beginning of pregnancy, cytotrophoblast cells of fetal origin migrate through the decidua and part of the myometrium to invade maternal spiral arteries that become larger caliber vessels of low resistance responsible for maintaining blood flow to the development of fetus and placenta (23). This invasion is regulated by several factors, including the cytotrophoblast differentiation from an epithelial to endothelial phenotype (a process called pseudovasculogenesis) (24) and the immunological interaction between HLA molecules $\mathrm{C}, \mathrm{E}$ and $\mathrm{G}$ and uterine natural killer cells $(25,26)$.

In preeclamptic women, cytotrophoblast cells do not express some adhesion molecules characteristic of endothelial phenotype, therefore they invade the decidual portion of spiral arteries but cannot penetrate the myometrium. Because of this abnormal remodeling, the spiral arteries do not develop in large vascular channels, resulting in placental hypoperfusion $(27,28)$. Placentation requires an extensive angiogenesis to establish an appropriate vascular network to supply fetal needs. The placenta produces a wide variety of proangiogenic proteins (vascular endothelial growth factor [VEGF] and placental growth factor [PIGF]), and antiangiogenic mediators such as soluble fms-like tyrosine kinase 1 (sFlt-1), whose balance determines the normal placental development (29). sFlt-1 is increased in placenta and serum of preeclamptic women, but this excessive release is still not fully understood (perhaps triggered by placental ischemia). This protein binds to VEGF and PIGF, preventing its interaction with endothelial receptors on the cell surface, inducing endothelial dysfunction (30-32). Another protein released by the placenta, soluble endoglin (sEng), also has an antiangiogenic role, but acts through a distinct mechanism of sFlt-1 (33). Both trigger endothelial dysfunction and severe preeclampsia $(34,35)$. The placental ischemia, reperfusion and associated oxidative stress amplify apoptosis by rupture of syncytial architecture and promote the release into the maternal circulation of several components (syncytiotrophoblast membrane microparticles and an excess of antiangiogenic factors, such 
as sFlt-1) that stimulate the synthesis of inflammatory cytokines (36-38). This excessive inflammatory response causes endothelial dysfunction, increased vascular reactivity and coagulopathy that precede the development of symptomatic disease (39).

\section{Clinical features}

The definition of preeclampsia is variable mainly in the cases with preexisting hypertension or proteinuria (11). The most widely accepted diagnostic criteria for preeclampsia are presented in Table II. Regarding the disease's severity, it is divided into 2 groups: mild and severe. Severe preeclampsia is indicated by more substantial blood pressure elevations, a greater degree of proteinuria and the presence of symptoms associated with target organ involvement (40). In recent years, a new concept has emerged depending on the time of disease development: early and late preeclampsia (41). Early preeclampsia (before the 34th week of gestation) is often associated with changes in uterine artery Doppler ultrasound results, fetal growth restriction and adverse maternal and perinatal outcomes. On the other hand, late preeclampsia (after the 34th week of gestation) seems to be strongly associated with maternal features (for example, body mass index), normal or slightly increased uterine artery

TABLE II

DIAGNOSTIC CRITERIA FOR PREECLAMPSIA

\section{Preeclampsia}

Blood pressure: systolic $\geq 140 \mathrm{~mm} \mathrm{Hg}$ or diastolic $\geq 90$ $\mathrm{mm} \mathrm{Hg}$, after 20 weeks of gestation in a previously normotensive woman

AND

Proteinuria: $\geq 300 \mathrm{mg}$ in a 24 -hour urine collection

\section{Severe preeclampsia}

Blood pressure: systolic $\geq 160 \mathrm{~mm} \mathrm{Hg}$ or diastolic $\geq 110$ $\mathrm{mm} \mathrm{Hg}$, on 2 occasions at least 6 hours apart

Proteinuria: $\geq 5 \mathrm{~g}$ in a 24 -hour urine collection

Symptoms associated with target organ involvement:

Cerebral and visual disturbances

Pulmonary edema

Epigastric or right upper quadrant pain

Impaired liver function

Thrombocytopenia

Oliguria resistance index (42) and minimal fetal involvement (43).

Usually the clinical manifestations are nonspecific even in severe disease. The most reported symptoms are epigastric or right upper quadrant pain (40\%-90\% of patients). Renal involvement in preeclampsia is common and results in a decreased renal plasma flow and GFR by $30 \%-40 \%$. However, serum creatinine often remains normal or slightly increased (1-1.5 mg/dL), except in severe preeclampsia, in which there is the development of moderate/severe AKI. Renal tubular function is also impaired in preeclampsia, with an early dysfunction of uric acid tubular secretion. Some authors correlate hyperuricemia with renal histological lesions, clinical severity and fetal survival (44). The urine sediment is usually benign. The histologic lesion associated with preeclampsia is glomerular endotheliosis, characterized by swelling and vacuolization of endothelial cells, capillary lumen occlusion, with no prominent podocyte alterations or thrombi in the capillaries and enlarged glomeruli (45). Immunofluorescence may reveal fibrin deposits.

\section{Preeclampsia risk factors and prevention}

At the first prenatal visit, it is possible to identify several factors that have been proven to increase the risk of preeclampsia development (see Tab. III) (24, 46-49). The detection of pregnant women at high risk for preeclampsia involves tighter monitoring of the pregnancy evolution, and some preventive measures may be indicated. Several studies show that daily supplementation with magnesium, fish oil, vitamin $C$ or $E$ is not effective $(25,50)$. Calcium supplementation in high-risk women and in those with a history of low calcium diet appears to reduce the risk of preeclampsia (51). A meta-analysis published by the Perinatal Antiplatelet Review of International Studies (PARIS) group demonstrated a moderate but consistent reduction in the relative risk of preeclampsia with aspirin use $(52,53)$.

\section{Maternal and perinatal outcomes}

The maternal and perinatal outcomes in preeclampsia depend on gestational age at onset, disease severity, type of care provided to the pregnant woman and presence of other maternal comorbid conditions. Generally, the prognosis is favorable for women with mild preeclampsia. Severe preeclampsia is associated with maternal, fetal or neonatal complications. The most frequent maternal complications are disseminated coagulopathy / HELLP syndrome (10\%-20\%), pulmonary edema (2\%-5\%), AKI (1\%-5\%) and placental abruption (1\%-4\%) $(21,54,55)$. Long-term epidemiologic studies point to an increased risk of cardiovascular disease 
(chronic hypertension, ischemic heart disease and stroke) in severe preeclamptic women (56-58). The fetal/neonatal complications that may occur in severe preeclampsia are fetal growth restriction (10\%-25\%), neurologic damage due to hypoxia $(<1 \%)$ and perinatal death (1.2\%) (54).

\section{HELLP SYNDROME}

Traditionally, the HELLP syndrome was considered to be a variant of preeclampsia, but it is, in fact, a distinct disease, since $20 \%$ of pregnant women with HELLP syndrome do not have a history of hypertension or proteinuria $(59,60)$. This obstetric entity affects $1-2$ women per 1,000 pregnancies (61), and its pathogenesis is not fully known. Similar preeclampsia mechanisms have been proposed particularly, the decline of proangiogenic mediators (PIGF) and the increase of antiangiogenic factors (sFlt-1 and sEng) (62).

HELLP syndrome occurs typically in the third trimester, but may be diagnosed in the second trimester or postpartum period (63). The clinical features are variable. Symptoms are mostly epigastric / right upper quadrant pain, nausea, vomiting and headache, but may manifest by its complications:

\section{TABLE III}

RISK FACTORS FOR PREECLAMPSIA

\section{Maternal obstetric factors}

Nulliparity

Multiple gestation pregnancy

History of preeclampsia

Molar pregnancy

\section{Obstetric paternal factors}

Father born from a preeclamptic pregnancy

\section{Maternal comorbid conditions}

Chronic hypertension

Renal disease

Pregestational diabetes mellitus

Obesity

Rheumatic disease

\section{Maternal genetic factors}

Antiphospholipid antibody

Factor V Leiden mutation

Preeclampsia in first-degree relative pregnancy

\section{Other maternal factors}

Age over 40 years disseminated intravascular coagulation, placental abruption, AKI (7\%-36\%), pulmonary edema, hepatic subcapsular hematoma and retinal detachment $(25,64,65)$.

The diagnosis of HELLP syndrome is based on the following laboratory criteria (64): (a) microangiopathic hemolytic anemia: schistocytes in blood smear, serum bilirubin $\geq 1.2$ $\mathrm{mg} / \mathrm{dL}$, lactate dehydrogenase $>600 \mathrm{U} / \mathrm{L}$; (b) increased liver transaminases (aspartate aminotransferase $>70 \mathrm{U} / \mathrm{L}$ ) and (c) platelet count $<100 \times 103$ cells $/ \mathrm{mm} 3$.

Maternal outcome in HELLP syndrome is favorable, often with analytic change normalization up to the sixth day after delivery. However, recovery may be delayed in more severe disease, including if AKI develops during pregnancy. Approximately $10 \%-46 \%$ of pregnant women with AKI associated with HELLP syndrome need dialysis in the acute phase $(66,67)$, but even these cases typically show a complete recovery of kidney function $(66,68)$. The most recent published studies refer maternal mortality of around 1\% (63). The perinatal mortality rate is higher, ranging between $7 \%$ and $34 \%$ and depends on gestational age and maternal disease severity $(59,63)$.

\section{ACUTE FATTY LIVER OF PREGNANCY}

Acute fatty liver of pregnancy (AFLP) is an obstetric emergency that, if left untreated, progresses to fulminant liver failure. AFLP incidence is 1 per 7,000 to 1 per 20,000 (69). The disease results from an autosomal recessive genetic error that causes a defect on long-chain 3-hydroxyacyl-CoA dehydrogenase, an enzyme involved in mitochondrial fatty acid beta-oxidation. There is an excessive fetal fatty acid accumulation to be released into the maternal circulation. The increased load of long-chain fatty acids is deposited in liver tissue and leads to impaired hepatic function in the mother (70). The histologic diagnosis of AFLP is based on the presence of lipid microvesicle infiltration of the hepatocytes, without inflammation or necrosis.

ALFP diagnosis depends upon clinical and laboratory findings. However, half of the patients have signs of preeclampsia/HELLP syndrome, and at an early phase, the differential diagnosis may be difficult (71) (Tab. IV). Liver biopsy allows for definitive diagnosis. AFLP occurs in the third trimester of pregnancy, and the early symptoms are nausea, vomiting and abdominal pain. Other signs settle as disease progresses - for example, jaundice and hepatic encephalopathy (72). Women with AFLP may also present thrombocytopenia with or without disseminated intravascular coagulation, hypoglycemia, intra-abdominal hemorrhage or central diabetes insipidus. Over $60 \%$ of pregnant women develop AKI, mostly mild and without need for di- 
alysis support $(73,74)$. The etiology of AKI in AFLP is multifactorial.

In most women, there is a complete liver and kidney recovery after delivery. However, AFLP is associated with an important maternal and perinatal mortality. Epidemiologic studies calculate a maternal and perinatal mortality between $10 \%$ and $20 \%(62,75-77)$.

\section{THROMBOTIC MICROANGIOPATHIES}

Pregnancy-associated thrombotic microangiopathies ( $\mathrm{p}$ TMA) are rare, affecting 1 per 25,000 pregnancies (78). They are defined by the presence of fibrin and/or platelet thrombi in the microcirculation of multiple organs (79). Depending on the most affected organ (brain or kidney), 2 clinical entities have been described: thrombotic thrombocytopenic purpura (TTP) and HUS. TTP is characterized by fever, thrombocytopenia (usually severe), microangiopathic hemolytic anemia, mild renal failure (creatinine $<1.4 \mathrm{mg} / \mathrm{dL}$ ) and neurologic symptoms (disorientation, ataxia, headache, focal changes, seizures or aphasia) (80). HUS clinical features are similar, but renal involvement is more pronounced (creatinine $>2.3$ $\mathrm{mg} / \mathrm{dL}$ ) and the presence of neurologic symptoms is rare. However, the clinical manifestations of these 2 entities may overlap, so in daily practice the distinction may be difficult. A disintegrin and metalloproteinase with thrombospondin motifs 13 (ADAMTS-13) is an enzyme produced by liver stellate cells, endothelial cells and platelets, responsible for cleaving ultralarge von Willebrand factor multimers (81). ADAMTS-13 deficiency allows the circulation of this highly thrombogenic multimer and causes platelet aggregation and red cell fragmentation, and PTT ensues. This enzymatic deficiency (defined by ADAMT-13 activity <10\%) (82) can be congenital, as a result of inactivating gene mutations (rare), or acquired, by circulating autoantibodies (67\%-83\% of cases) $(79,83,84)$. The pathogenesis of atypical HUS (i.e., non-Shiga-like-toxinassociated HUS) is not as fully understood. It seems to be associated with a dysregulation of the alternative complement pathway that leads to lesions in multiple body cells, namely endothelial cells. Several regulatory (factor $\mathrm{H}$ and I, membrane cofactor protein [MCP,or CD46] and decay-accelerating factor [DAF] and activation factor [C3 and factorB] molecules are

\section{TABLE IV}

SEVERE PREECLAMPSIA, HELLP SYNDROME, ACUTE FATTY LIVER OF PREGNANCY AND THROMBOTIC MICROANGIOPATHY: DIFFERENTIAL DIAGNOSIS

\begin{tabular}{|c|c|c|c|c|c|}
\hline & $\begin{array}{c}\text { Severe } \\
\text { preeclampsia }\end{array}$ & HELLP & AFLP & TTP & aHUS \\
\hline Time of diagnosis & Usually $3 T$ & 3 & & Usually $2 \mathrm{~T} / 3 \mathrm{~T}$ & Postpartum \\
\hline Frequency of hypertension & $100 \%$ & $80 \%$ & $25 \%-50 \%$ & $0 /+$ & + \\
\hline Fever / neurologic symptoms & no & no & no & yes & no \\
\hline Acute kidney Injury & mild & mild / moderate & moderate & mild / moderate & severe \\
\hline Hemolytic anemia & 0 & + & $0 /+$ & ++ & + \\
\hline Thrombocytopenia & $0 /+$ & + & 0 & ++ & ++ \\
\hline Liver transaminase increase & $0 /+$ & + & ++ & 0 & 0 \\
\hline $\begin{array}{l}\text { Partial thromboplastin time } \\
\text { increase }\end{array}$ & $0 /+$ & $0 /+$ & + & 0 & 0 \\
\hline ADAMTS-13 activity $<10 \%$ & 0 & 0 & 0 & ++ & + \\
\hline Recovery after delivery & 2-3 days & 1 week & $1-2$ days & \multicolumn{2}{|c|}{ No recovery } \\
\hline Treatment & \multicolumn{3}{|c|}{ Delivery; Support measures } & \multicolumn{2}{|c|}{ Plasma infusion /exchange } \\
\hline
\end{tabular}

0 = absence; $0 /+=$ occasionally present; + = sometimes present; ++ = always present; AFLP = acute fatty liver of pregnancy; aHUS = atypical hemolytic uremic syndrome; HELLP = hemolysis, elevated liver enzymes and low platelet count, TTP = thrombotic thrombocytopenic purpura; $2 \mathrm{~T}$ = second trimester of gestation; $3 \mathrm{~T}$ = third trimester of gestation. 
involved in this complement pathway. Atypical HUS may then result from: (i) constitutional factors: inactivating mutations of the genes that encode the factors $\mathrm{H}, \mathrm{I}$ and $\mathrm{MCP}$, or activating gene mutations for factor $\mathrm{B}$ and $\mathrm{C} 3$; (ii) acquired factors : antifactor $\mathrm{H}$ antibodies $(83,84)$. ADAMTS-13 activity is normal in atypical HUS - a distinct aspect from PTT. Not all individuals with these genetic changes associated with HUS-PTT pathogenesis will develop disease. This fact reveals the need for triggering factors, such as pregnancy.

The p-TMA may occur any time during pregnancy or at puerperium, in previously healthy women. TTP is often diagnosed before delivery, especially in the second and third trimesters (85) because the ADAMTS-13 level physiologically tends to decrease during the last trimester $(81,86)$. Atypical HUS occurs mainly in the first 6 months after delivery (87). The diagnosis of p-TMA is clinically challenging, due to the need to exclude other specific pregnancy thrombotic diseases, such as preeclampsia and HELLP syndrome (see Tab. IV).

The $\mathrm{p}$-TMA renal involvement is common, and AKI is present in two thirds of cases (1). Most patients have severe renal failure requiring dialysis therapy (84). The kidney disease results from renal thrombotic microangiopathy and is morphologically characterized by multiple intraluminal thrombi; double contour appearance of capillary basement membrane; mesangiolysis; and arterial and arteriolar changes, including mucoid intimal thickening, fibrinoid necrosis or thrombosis (88). The maternal mortality in $\mathrm{p}$-TMA has declined in recent years and is now between $10 \%$ and $20 \%(1,85)$. However, the latest epidemiologic data indicate a high perinatal mortality rate $(30 \%-80 \%)$ caused mainly by growth restriction and placental infarction due to thrombosis of decidua arterioles (1). The long-term renal outcome is poor. Seventy-six percent of patients with AKI related to $\mathrm{p}$-TMA develop endstage chronic kidney disease $(84,89)$.

\section{AKI TREATMENT IN PREGNANCY}

There are 3 aspects to consider in the management of AKI related to pregnancy: (a) renal function supportive measures, (b) dialysis and (c) treatment of the underlying disease.

\section{Renal function supportive measures}

Some important general measures to minimize renal injury (such as etiology treatment, suspension of nephrotoxic drugs or treatment of an infectious disease) should be started as soon as possible. The second step is administration of intravenous fluids to restore or maintain renal perfusion $(90$, 91). This procedure also prevents hypovolemia and ensures an adequate uteroplacental perfusion and fetal well-being.
These general measures are followed by pharmacologic therapy of AKI and its known complications: hypertension, hyperkalemia, metabolic acidosis and anemia. Hypertension is a frequent sign in AKI related to pregnancy. There is no consensus about the level at which we should start antihypertensive medications (40). Some of the antihypertensive drugs commonly used in the general population are contraindicated in pregnancy (such as angiotensin-converting enzyme inhibitors and angiotensin II receptor antagonists) or are not recommended (such as diuretics because of the high risk for volume depletion). Therefore the first-line treatment options in pregnant women are methyldopa and labetalol (92). The dihydropyridine calcium channel blockers can also be used successfully and safely in pregnancy. Hydralazine is more commonly used in severe hypertension $(3,93)$; however, its use has recently been associated with adverse maternal and fetal outcomes (94). The administration of insulin, glucose and ion exchange resin are recommended for the treatment of hyperkalemia. There are no published data about the resin use in pregnant women, but this drug has a local action within the gastrointestinal tract, therefore, there is no reason for a fetal deleterious effect. In the healthy pregnant woman, a $4 \mathrm{mEq} / \mathrm{L}$ decrease in bicarbonate concentration is common. This fact has to be taken into account when correcting metabolic acidosis with sodium bicarbonate. Regarding anemia associated with AKI, blood transfusion is recommended in acute therapy. The erythropoiesis-stimulating agents are safe in pregnancy, but higher doses are usually required to obtain the desired therapeutic effect (95).

\section{Dialysis}

If the previous procedures prove to be insufficient, dialysis is the next step. The indications for dialysis are the same as for the general population with severe AKI: uremic symptoms (encephalopathy, pericarditis or neuropathy), volume overload, hyperkalemia and/or metabolic acidosis unresponsive to initial medical treatment. However, authors recommend starting dialysis earlier, when GFR falls to below $20 \mathrm{ml} / \mathrm{min}$ per $1.73 \mathrm{~m}^{2}(3)$. Any dialysis modality can be used in pregnancy because there are no randomized studies showing benefits for a specific technique. In most cases, the choice is intermittent hemodialysis. Some aspects must be taken into account when prescribing dialysis in pregnant women. Increasing the dialysis dose leads to an increase in fetal survival and prematurity decrease (96). So a daily dialysis program (more than 20 hours/week) $(1,95)$ should be established to: (a) improve the uremic environment, a high risk factor for prematurity and polyhydramnios, (b) minimize hemodynamic fluctuations of hemodialysis that adversely 


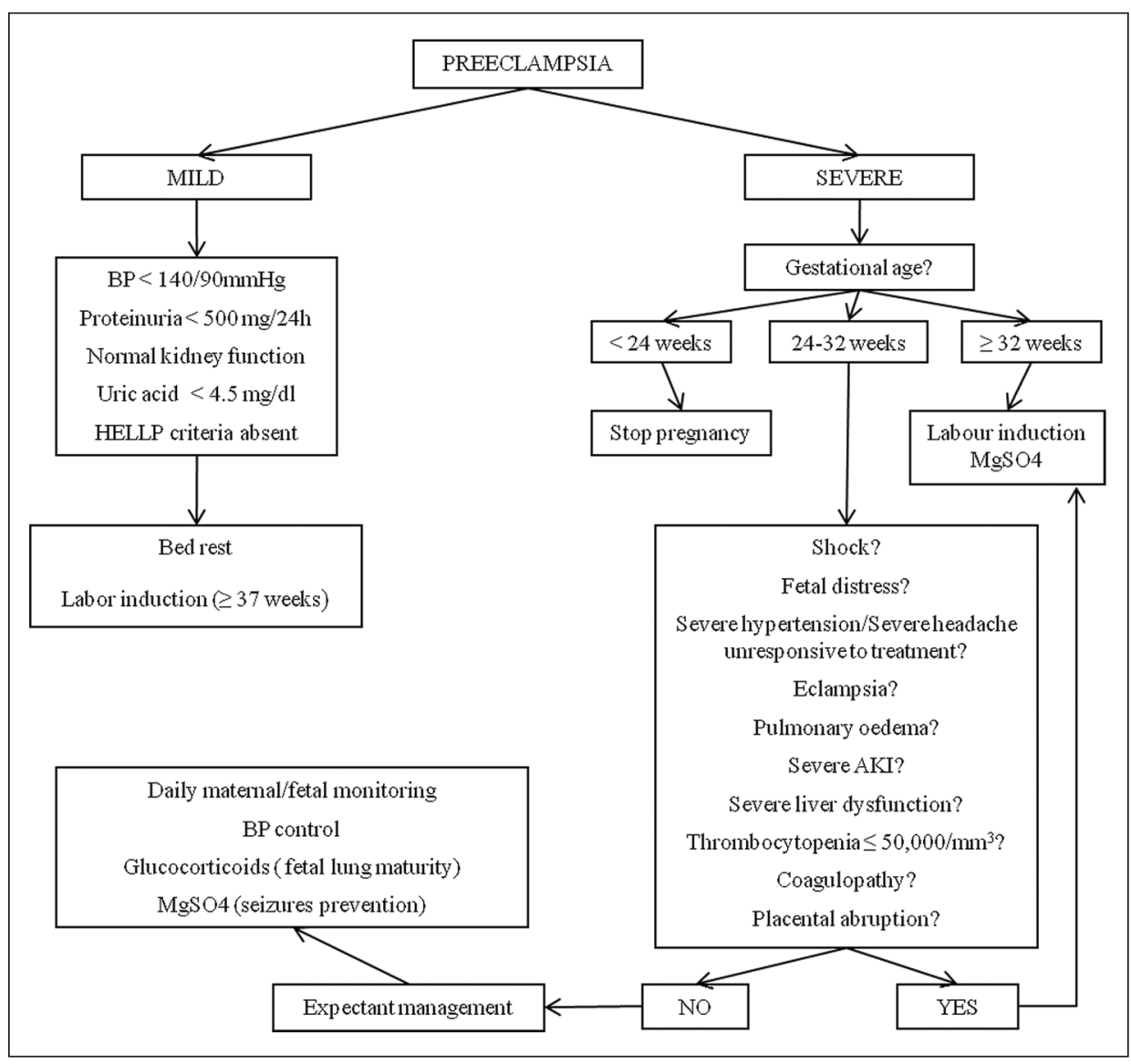

Fig. 1 - Proposed algorithm for the management of preeclampsia. AKI $=$ acute kidney injury; $\mathrm{BP}=$ blood pressure; HELLP = hemolysis, elevated liver enzymes and low platelet count; $\mathrm{MgSO}_{4}=$ magnesium sulphate.

affect uteroplacental perfusion and increase the risk of placental oxidative stress. When establishing a dry weight, it is important not to forget the normal weight gain (0.3-0.5 $\mathrm{kg} /$ week) in the second and third trimesters (78). Some dialysate parameters should be tailored in pregnant women, such as bicarbonate to $25 \mathrm{mEq} / \mathrm{L}$ and sodium to $135 \mathrm{mEq} / \mathrm{L}$ (97). Heparin and low-molecular-weight heparin are safe in pregnancy because they do not cross the placental barrier. Both can be used during hemodialysis treatment (3).

\section{Treatment of the underlying disease}

\section{Preeclampsia/HELLP syndrome}

The treatment of severe preeclampsia/HELLP syndrome depends on illness severity, gestational age and fetal wellbeing. Figure 1 represents a proposed algorithm for preeclampsia management.

Before 24 weeks of gestation, pregnancy discontinuance is recommended since studies show no fetal survival benefit and only increase the risk of severe maternal complications $(25,98)$. Between 24 and 32 weeks of gestation, the expectant management is a reasonable approach (3). Delivery is the treatment of choice for pregnancies $\geq 32$ weeks $(25,71$, 99). Some clinical situations are considered indications for prompt delivery regardless of gestational age: worsening maternal condition, eclampsia or signs of fetal compromise (3). Some studies show the benefit of corticosteroid therapy for the prognosis of HELLP syndrome. However, the results of the only randomized controlled trial published to date do not show any impact on length of hospitalization, on the speed of recovery or the development of complications (94).

\section{AFLP}

In AFLP, the stabilization of the maternal clinical condition through glycemic control with glucose administration and coagulopathy correction with fresh frozen plasma, blood transfusion or cryoprecipitate is essential. Hepatic encephalopathy is treated with low protein diet and oral lactulose. Delivery should be induced immediately to avoid progression to liver failure. Other interventions may be necessary in more severe cases, including mechanical ventilation, parenteral nutrition, surgery or even liver transplantation $(1,71)$. Recent case reports have described successful treatment of this condition with mo- 
lecular adsorbent recirculating systems (MARS); however, its practical application has yet to be validated (94).

\section{HUS/TTP}

TTP treatment includes fresh frozen plasma infusion and plasmapheresis (94) to correct ADAMTS-13 deficiency and remove the ADAMTS-13 circulating antibody. In suspected cases of autoimmune ADAMTS-13 deficiency, steroids are recommended as initial immunosuppressive therapy. Some published data report the use of cyclosporine and rituximab in patients with more serious disease (80). Response to therapy is best monitored by following serial serum lactate dehydrogenase. Treatment of atypical HUS also includes plasma infusion and plasma exchange to restore the missing mediators (factors $\mathrm{H}$ and $\mathrm{I}$ ) and remove anti-factorH (79, 84). Delivery does not have any influence on disease remission, but should be promptly induced if there is serious illness and/or a viable fetus. Platelet transfusions should be avoided if possible, because of the risk for increased microvascular thrombosis.

\section{Conclusion}

The development of AKI in pregnancy is a major clinical challenge because it is necessary to consider 2 patients (mother and fetus) and can be caused by specific pregnancy diseases not yet fully understood. It is essential to focus on the prevention and periodic evaluation of pregnant women to improve maternal and perinatal outcomes. The complexity of the AKI in pregnancy requires a multidisciplinary approach where the nephrologist plays an important role.

Financial support: This review had no financial support.

Conflict of interest statement: None declared.

Address for correspondence:

Dr. Susana Machado

Hospitais da Universidade de Coimbra

Praceta Professor Mota Pinto

PT-3000-075 Coimbra, Portugal

susana_machado_@hotmail.com

\section{References}

1. Gammill HS, Jeyabalan A. Acute renal failure in pregnancy. Crit Care Med. 2005;33(10)(Suppl):S372-S384.

2. Rasmussen PE, Nielsen FR. Hydronephrosis during pregnancy: a literature survey. Eur J Obstet Gynecol Reprod Biol. 1988;27(3):249-259.

3. Krane NK, Hamrahian M. Pregnancy: kidney diseases and hypertension. Am J Kidney Dis. 2007;49(2):336-345.

4. Danielson LA, Kercher LJ, Conrad KP. Impact of gender and endothelin on renal vasodilation and hyperfiltration induced by relaxin in conscious rats. Am J Physiol Regul Integr Comp Physiol. 2000;279(4):R1298-R1304.

5. Fekete A, Sasser JM, Baylis C. Chronic vasodilation produces plasma volume expansion and hemodilution in rats: consequences of decreased effective arterial blood volume. Am J Physiol Renal Physiol. 2011;300(1):F113-F118.

6. Conrad KP, Lindheimer M. Renal and cardiovascular alterations. In: Lindheimer M, Roberts J, Cunningham F, eds. Chesley's hypertensive disorders in pregnancy. 3rd ed. Amsterdam: Elsevier. 2009:297-334.

7. Jeyabalan A, Conrad KP. Renal function during normal pregnancy and preeclampsia. Front Biosci. 2007;12(1):2425-2437.

8. August P. The patient with kidney disease and hypertension in pregnancy. In: Schrier RW, ed. Manual of nephrology. 7th ed. Philadelphia, PA: Lippincott Williams \& Wilkins. 2009:220-243.

9. Zhu Y, Goff JP, Reinhardt TA, Horst RL. Pregnancy and lactation increase vitamin D-dependent intestinal membrane calcium adenosine triphosphatase and calcium binding protein messenger ribonucleic acid expression. Endocrinology. 1998;139(8):3520-3524.

10. August $P$. The kidney in pregnancy. In: Greenberg A, Cheung A, Falk R, Coffman T, Jeannette J, eds. Primer on kidney diseases. 4th ed. National Kidney Foundation;National Kidney Foundation; Philadephia, PA. 2005:426-435.

11. Piccoli GB, Conijn A, Attini R, et al. Pregnancy in chronic kidney disease: need for a common language. J Nephrol. 2011;24(3):282-299.

12. Lafayette R. AKI in pregnant patient: two lives at stake. Nephrology Times. 2010;3(5):9-10.

13. Smith MC, Moran P, Ward MK, Davison JM. Assessment of 
glomerular filtration rate during pregnancy using the MDRD formula. BJOG. 2008;115(1):109-112.

14. Alper AB, Yi Y, Webber LS, et al. Estimation of glomerular filtration rate in preeclamptic patients. Am J Perinatol. 2007;24(10):569-574.

15. Rodriguez-Thompson D, Lieberman ES. Use of a random urinary protein-to-creatinine ratio for the diagnosis of significant proteinuria during pregnancy. Am J Obstet Gynecol. 2001;185(4):808-811.

16. Maynard SE, Thadhani R. Pregnancy and the kidney. J Am Soc Nephrol. 2009;20(1):14-22.

17. Chan P, Brown M, Simpson JM, Davis G. Proteinuria in preeclampsia: how much matters? BJOG. 2005;112(3):280-285.

18. Martins-Costa SH, Vettorazzi J, Valério E, et al. Protein creatinine ratio in random urine sample of hypertensive pregnant women: maternal and perinatal outcomes. Hypertens Pregnancy. 2011;30(3):331-337.

19. Prakash J, Niwas SS, Parekh A, et al. Acute kidney injury in late pregnancy in developing countries. Ren Fail. 2010;32(3):309-313.

20. Dragun K, Haase M. Acute kidney failure during pregnancy and postpartum. In: Jörres A, Ronco C, Kellum J, eds. Management of acute kidney problems. Springer; Berlin. 2010:445-458.

21. Sibai B, Dekker G, Kupferminc M. Pre-eclampsia. Lancet. 2005;365(9461):785-799.

22. Carty DM, Delles C, Dominiczak AF. Preeclampsia and future maternal health. J Hypertens. 2010;28(7):1349-1355.

23. Forbes $\mathrm{K}$, Westwood M. Maternal growth factor regulation of human placental development and fetal growth. J Endocrinol. 2010;207(1):1-16.

24. Khankin EV, Royle C, Karumanchi SA. Placental vasculature in health and disease. Semin Thromb Hemost. 2010;36(3): 309-320.

25. Hu Y, Dutz JP, MacCalman CD, Yong P, Tan R, von Dadelszen $P$. Decidual NK cells alter in vitro first trimester extravillous cytotrophoblast migration: a role for IFN-y. J Immunol. 2006; 177(12):8522-8530.

26. Steegers EA, von Dadelszen P, Duvekot JJ, Pijnenborg R. Pre-eclampsia. Lancet. 2010;376(9741):631-644.

27. Karumanchi SA, Maynard SE, Stillman IE, Epstein FH, Sukhatme VP. Preeclampsia: a renal perspective. Kidney Int. 2005;67(6):2101-2113.

28. Yagel S. Angiogenesis in gestational vascular complications. Thromb Res. 2011;127(Suppl 3):S64-S66.

29. Maynard S, Epstein FH, Karumanchi SA. Preeclampsia and angiogenic imbalance. Annu Rev Med. 2008;59(1):61-78.

30. Levine RJ, Maynard SE, Qian C, et al. Circulating angiogenic factors and the risk of preeclampsia. $\mathrm{N}$ Engl $\mathrm{J}$ Med. 2004;350(7):672-683.

31. Silasi M, Cohen B, Karumanchi SA, Rana S. Abnormal placentation, angiogenic factors, and the pathogenesis of preeclampsia. Obstet Gynecol Clin North Am. 2010;37(2): 239-253.
32. Kita N, Mitsushita J. A possible placental factor for preeclampsia: sFlt-1. Curr Med Chem. 2008;15(7):711-715.

33. Venkatesha S, Toporsian M, Lam C, et al. Soluble endoglin contributes to the pathogenesis of preeclampsia. Nat Med. 2006;12(6):642-649.

34. Chen Y. Novel angiogenic factors for predicting preeclampsia: sFIt-1, PIGF and soluble endoglin. Open Clinical Chemistry Journal. 2009;2:1-6.

35. Foidart JM, Schaaps JP, Chantraine F, Munaut C, Lorquet S. Dysregulation of anti-angiogenic agents (sFlt-1, PLGF, and sEndoglin) in preeclampsia: a step forward but not the definitive answer. J Reprod Immunol. 2009;82(2):106-111.

36. Gupta S, Agarwal A, Sharma RK. The role of placental oxidative stress and lipid peroxidation in preeclampsia. Obstet Gynecol Surv. 2005;60(12):807-816.

37. Matthiesen L, Berg G, Ernerudh J, Ekerfelt C, Jonsson Y, Sharma S. Immunology of preeclampsia. Chem Immunol Allergy. 2005;89:49-61.

38. Redman CW, Sargent IL. Circulating microparticles in normal pregnancy and pre-eclampsia. Placenta. 2008; 29(Suppl A):S73-S77

39. Redman CW, Sargent IL. Pre-eclampsia, the placenta and the maternal systemic inflammatory response: a review. Placenta 2003;24(Suppl A):S21-S27.

40. Leeman L, Fontaine P. Hypertensive disorders of pregnancy. Am Fam Physician. 2008;78(1):93-100.

41. Paruk F, Moodley J. Maternal and neonatal outcome in early- and late-onset pre-eclampsia. Semin Neonatol. 2000; 5(3):197-207.

42. Melchiorre K, Wormald B, Leslie K, Bhide A, Thilaganathan B. First-trimester uterine artery Doppler indices in term and preterm pre-eclampsia. Ultrasound Obstet Gynecol. 2008;32(2):133-137.

43. Valensise H, Vasapollo B, Gagliardi G, Novelli GP. Early and late preeclampsia: two different maternal hemodynamic states in the latent phase of the disease. Hypertension. 2008;52(5):873-880.

44. Koopmans CM, van Pampus MG, Groen H, Aarnoudse JG, van den Berg PP, Mol BW. Accuracy of serum uric acid as a predictive test for maternal complications in pre-eclampsia: bivariate meta-analysis and decision analysis. Eur J Obstet Gynecol Reprod Biol. 2009;146(1):8-14.

45. Karumanchi S, Epstein F. Renal complications in pregnancy. In: Feehally J, Floege J, Johnson R, eds. Comprehensive clinical nephrology. 3rd ed. Mosby; Philadelphia, PA. 2007.

46. Turner JA. Diagnosis and management of pre-eclampsia: an update. Int J Womens Health. 2010;2:327-337.

47. Skjaerven R, Vatten LJ, Wilcox AJ, Rønning T, Irgens LM, Lie RT. Recurrence of pre-eclampsia across generations: exploring fetal and maternal genetic components in a population based cohort. BMJ. 2005;331(7521):877.

48. Catalano PM. Obesity, insulin resistance, and pregnancy outcome. Reproduction. 2010;140(3):365-371.

49. Jacquemyn Y, Zemtsova O. Risk factors and prediction of 
preeclampsia. Acta Clin Belg. 2010;65(1):1-12.

50. Barton JR, Sibai BM. Prediction and prevention of recurrent preeclampsia. Obstet Gynecol. 2008;112(2, Part 1) (2 Pt 1):359-372.

51. Hofmeyr GJ, Lawrie TA, Atallah AN, Duley L. Calcium supplementation during pregnancy for preventing hypertensive disorders and related problems. Cochrane Database Syst Rev. 2010;(8):CD001059.

52. Askie LM, Duley L, Henderson-Smart DJ, Stewart LA; PARIS Collaborative Group. Antiplatelet agents for prevention of pre-eclampsia: a meta-analysis of individual patient data. Lancet. 2007;369(9575):1791-1798.

53. Duley L, Henderson-Smart DJ, Meher S, King JF. Antiplatelet agents for preventing pre-eclampsia and its complications. Cochrane Database Syst Rev. 2007;(2):CD004659.

54. Hauth JC, Ewell MG, Levine RJ, et al; Calcium for Preeclampsia Prevention Study Group. Pregnancy outcomes in healthy nulliparas who developed hypertension. Obstet Gynecol. 2000;95(1):24-28.

55. Bombrys AE, Barton JR, Nowacki EA, et al. Expectant management of severe preeclampsia at less than 27 weeks' gestation: maternal and perinatal outcomes according to gestational age by weeks at onset of expectant management. Am J Obstet Gynecol. 2008;199(3):247, e1-e6.

56. Romundstad PR, Magnussen EB, Smith GD, Vatten LJ. Hypertension in pregnancy and later cardiovascular risk: common antecedents? Circulation. 2010;122(6):579-584.

57. Terry MB, Perrin M, Salafia CM, et al. Preeclampsia, pregnancy-related hypertension, and breast cancer risk. Am J Epidemiol. 2007;165(9):1007-1014.

58. Strobl I, Windbichler G, Strasak A, et al. Left ventricular function many years after recovery from pre-eclampsia. BJOG. 2011;118(1):76-83.

59. Sibai BM. Diagnosis, controversies, and management of the syndrome of hemolysis, elevated liver enzymes, and low platelet count. Obstet Gynecol. 2004;103(5 Pt 1):981-991.

60. Barton JR, Sibai BM. Gastrointestinal complications of preeclampsia. Semin Perinatol. 2009;33(3):179-188.

61. Pan C, Perumalswami PV. Pregnancy-related liver diseases. Clin Liver Dis. 2011;15(1):199-208.

62. Joshi D, James A, Quaglia A, Westbrook RH, Heneghan MA. Liver disease in pregnancy. Lancet. 2010;375(9714):594-605.

63. Picinni P, Gallo G. Diagnosis and management of HELLP syndrome. In: Ronco C, Bellomo R, Kellum J, eds. Critical care nephrology. 2nd ed. Saunders; Philadelphia, PA. 2009:337-340.

64. Haram K, Svendsen E, Abildgaard U. The HELLP syndrome: clinical issues and management: a Review. BMC Pregnancy Childbirth. 2009;9(1):8.

65. Baxter JK, Weinstein L. HELLP syndrome: the state of the art. Obstet Gynecol Surv. 2004;59(12):838-845.

66. Drakeley AJ, Le Roux PA, Anthony J, Penny J. Acute renal failure complicating severe preeclampsia requiring admission to an obstetric intensive care unit. Am J Obstet Gynecol.
2002;186(2):253-256.

67. Celik C, Gezginç K, Altintepe L, et al. Results of the pregnancies with HELLP syndrome. Ren Fail. 2003;25(4):613-618.

68. Gul A, Aslan H, Cebeci A, Polat I, Ulusoy S, Ceylan Y. Maternal and fetal outcomes in HELLP syndrome complicated with acute renal failure. Ren Fail. 2004;26(5):557-562.

69. Knight M, Nelson-Piercy C, Kurinczuk JJ, Spark P, Brocklehurst P; UK Obstetric Surveillance System. A prospective national study of acute fatty liver of pregnancy in the UK. Gut. 2008;57(7):951-956.

70. Lee NM, Brady CW. Liver disease in pregnancy. World J Gastroenterol. 2009;15(8):897-906.

71. Guntupalli SR, Steingrub J. Hepatic disease and pregnancy: an overview of diagnosis and management. Crit Care Med. 2005;33(10)(Suppl):S332-S339.

72. Wei Q, Zhang L, Liu X. Clinical diagnosis and treatment of acute fatty liver of pregnancy: a literature review and 11 new cases. J Obstet Gynaecol Res. 2010;36(4):751-756.

73. Santana L, Hernández Medina E, O'Shanahan G, Sánchez-Palacios M. Acute renal failure in acute fatty liver of pregnancy: apropos of a case. Nefrologia. 2005;25(4): 453-454.

74. Koroshi A, Babameto A. Acute renal failure during acute fatty liver of pregnancy. Nephrol Dial Transplant. 2002;17(6):1110-1112.

75. Fesenmeier MF, Coppage KH, Lambers DS, Barton JR, Sibai BM. Acute fatty liver of pregnancy in 3 tertiary care centers. Am J Obstet Gynecol. 2005;192(5):1416-1419.

76. Ko H, Yoshida EM. Acute fatty liver of pregnancy. Can J Gastroenterol. 2006;20(1):25-30.

77. Westbrook RH, Yeoman AD, Joshi D, et al. Outcomes of severe pregnancy-related liver disease: refining the role of transplantation. Am J Transplant. 2010;10(11):2520-2526.

78. Matthews JH, Benjamin S, Gill DS, Smith NA. Pregnancy-associated thrombocytopenia: definition, incidence and natural history. Acta Haematol. 1990;84(1):24-29.

79. Fakhouri F, Frémeaux-Bacchi V. Does hemolytic uremic syndrome differ from thrombotic thrombocytopenic purpura? Nat Clin Pract Nephrol. 2007;3(12):679-687.

80. George J. The thrombotic thrombocytopenic purpura and hemolytic uremic syndrome: evaluation, management and long-term outcomes experience of the Oklahoma TTP-HUS registry, 1989-2007. Kidney Int. 2009;112:S52-S54.

81. Mannucci PM, Canciani MT, Forza I, Lussana F, Lattuada A, Rossi E. Changes in health and disease of the metalloprotease that cleaves von Willebrand factor. Blood. 2001;98(9): 2730-2735.

82. Vesely SK, George JN, Lämmle B, et al. ADAMTS13 activity in thrombotic thrombocytopenic purpura-hemolytic uremic syndrome: relation to presenting features and clinical outcomes in a prospective cohort of 142 patients. Blood. 2003;102(1):60-68.

83. Besbas N, Karpman D, Landau D, et al; European Paediatric Research Group for HUS. A classification of hemo- 
lytic uremic syndrome and thrombotic thrombocytopenic purpura and related disorders. Kidney Int. 2006;70(3): 423-431.

84. Fakhouri F, Roumenina L, Provot F, et al. Pregnancy-associated hemolytic uremic syndrome revisited in the era of complement gene mutations. J Am Soc Nephrol. 2010;21(5): 859-867.

85. Martin JN Jr, Bailey AP, Rehberg JF, Owens MT, Keiser SD, May WL. Thrombotic thrombocytopenic purpura in 166 pregnancies: 1955-2006. Am J Obstet Gynecol. 2008;199(2): 98-104.

86. George JN. The association of pregnancy with thrombotic thrombocytopenic purpura-hemolytic uremic syndrome. Curr Opin Hematol. 2003;10(5):339-344.

87. Ruggenenti P, Cravedi P, Remuzzi G. Thrombotic microangiopathies including hemolytic uremic syndrome. In: Floege J, Johnson R, Feehally J, eds. Comprehensive clinical nephrology. 4th ed. Mosby; Philadelphia, PA. 2010:344-355.

88. Laszik Z. Thrombotic microangiopathies. In: Silva F, D'Agati V, Nadasdy T, eds. Renal biopsy interpretation. Churchill Livingstone; Oklahoma. 1996.

89. Grünfeld JP, Pertuiset N. Acute renal failure in pregnancy: 1987. Am J Kidney Dis. 1987;9(4):359-362.

90. Jeong JY, Kim SH, Lee HJ, Sim JS. Atypical low-signal-intensity renal parenchyma: causes and patterns. Radiographics. 2002;22(4):833-846.

91. Brown M, Mangos G, Peek M, Plaat F. Renal disease in pregnancy. In: Powrin R, Greene M, Camman W, eds. De Swiet's medical disorders in obstetric practice. 5th ed. Wiley-Blackwell; Oxford. 2010.
92. Vidaeff AC, Carrol MA, Rami SM. Acute hypertensive emergencies in pregnancy. Crit Care Med 2005;33(10 Suppl):S307:S312

93. Souza AR, Amorim MR, Costa AA, Neto CN. Antihypertensive treatment in pregnancy. Acta Med Port 2010;23(1):77-84

94. Ganesan C, Maynard SE. Acute kidney injury in pregnancy: the thrombotic microangiopathies. J Nephrol. 2011; pii: DE59A637-F706-47BF-931E-A6857A01DB8A [ePub Jan14].

95. Anantharaman $P$, Schimdt R, Holley J. Pregnancy \& renal diseases. In: Nissenson A, Berns J, Lerma E, eds. Current diagnosis and treatment: nephrology and hypertension, McGraw-Hill; International Edition. 2009:497-498.

96. Okundaye I, Abrinko P, Hou S. Registry of pregnancy in dialysis patients. Am J Kidney Dis. 1998;31(5):766-773.

97. Lindheimer M, Conrad K, Umans J. The normal and disease kidney in pregnancy. In: Schrier R, ed. Diseases of the kidney and urinary tract. Vol. 3; 8th ed. Philadelphia, PA: Lippincott Williams \& Wilkinson; 2007:1933.

98. Magee LA, Yong PJ, Espinosa V, Côté AM, Chen I, von Dadelszen P. Expectant management of severe preeclampsia remote from term: a structured systematic review. Hypertens Pregnancy. 2009;28(3):312-347.

99. Gaugler-Senden IP, Huijssoon AG, Visser W, Steegers EA, de Groot CJ. Maternal and perinatal outcome of preeclampsia with an onset before 24 weeks' gestation: audit in a tertiary referral center. Eur J Obstet Gynecol Reprod Biol. 2006;128(1-2):216-221.

Accepted: July 13, 2011 